\title{
Detection of creatinine using surface-driven ordering transitions of liquid crystals
}

\author{
Indu Verma ${ }^{[\mathrm{a}]}$ Sumyra Sidiq ${ }^{[\mathrm{a}]}$ and Santanu Kumar Pal ${ }^{*[\mathrm{a}]}$ \\ ${ }^{[a]}$ Department of Chemical Sciences, Indian Institute of Science Education and Research \\ (IISER) Mohali, Sector-81, Knowledge City, Manauli-140306, India \\ E-mail:skpal@iisermohali.ac.in
}
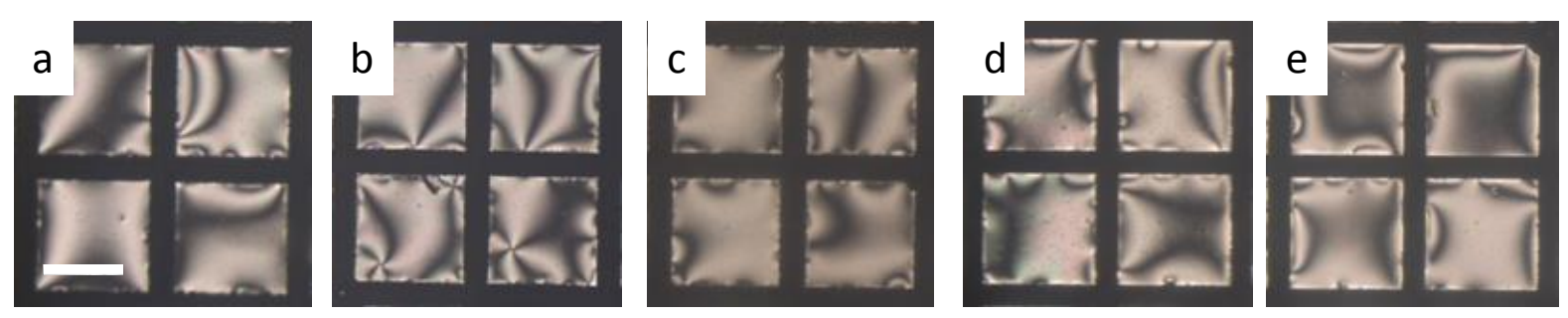

Figure S1. Polarized light microscopy images of the response of HBA doped LCs when $40 \mu \mathrm{M}$ creatinine was hydrolysed by a) 80, b) 40 , c) 10 , d) 8 , and e) $5 \mu \mathrm{g} \mathrm{ml}^{-1}$ creatinine deiminase. Scale bar $=200 \mu \mathrm{m}$. 

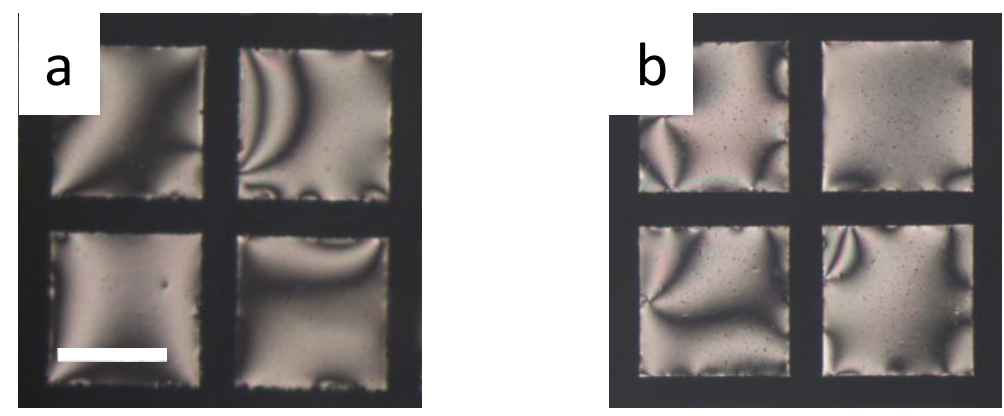

Figure S2. Polarized microscopy images of the HBA doped LCs when $0.04 \mathrm{mg} \mathrm{ml}^{-1}$ creatinine deiminase is introduced in mixture of $0.1 \mu \mathrm{M}$ human hemoglobin, $5 \mathrm{mM}$ glucose and $0.08 \mathrm{mM} \mathrm{L-}$ ascorbic acid at (a) $0 \mathrm{sec}$ (b) 3 hours. Scale bar $=200 \mu \mathrm{m}$ 